\title{
Influence of medium composition on the characteristics of a denitrifying biofilm formed by Alcaligenes denitrificans in a fluidised bed reactor
}

\author{
C.F. Alves ${ }^{a}$, L.F. Melo ${ }^{b}$, M.J. Vieira ${ }^{a, *}$ \\ ${ }^{a}$ Centro de Engenharia Biológica-IBQF, Universidade do Minho, Campus de Gualtar, 4710-057 Braga, Portugal \\ ${ }^{\mathrm{b}}$ Faculty of Engineering of Porto, Department of Chemical Engineering, LEPAE, 4200-465 Oporto, Portugal
}

Received 14 May 2001; received in revised form 22 July 2001; accepted 12 August 2001

\begin{abstract}
The influence of the ratio carbon/nitrogen and phosphorus concentration on the performance of a biofilm fluidised bed reactor used for denitrification and on the properties of the biofilm was studied. Although the removal efficiencies of $\mathrm{C}$ and $\mathrm{N}$ reached steady-state values, the thickness of the biofilm steadily increased. The dry density of the biofilm did not seem to be dependent on the loading conditions, although a denser biofilm was obtained when there was no nutrient limitation that corresponded to the complete removal of nitrate and carbon. The composition of the biofilm in terms of proteins and polysaccharides changed with the $\mathrm{C} / \mathrm{N}$ ratio and $\mathrm{P}$ concentrations. Higher denitrifying activities, which were obtained with increasing $\mathrm{P}$ concentrations, were related with higher protein content, since metabolism was shifted from polysaccharide production towards cell production. The thickness and the density of the biofilms were related mainly with the shear stress in the reactor and the composition of biofilms was dependent on the composition of the medium and related with higher activities of the microorganisms. (C) 2002 Elsevier Science Ltd. All rights reserved.
\end{abstract}

Keywords: Biofilm fluidised reactors; Denitrification; Biofilm characteristics; Density; Carbon/Nitrogen ratio; Phosphorus

\section{Nomenclature}

$\mathrm{C} / \mathrm{N} \quad$ ratio carbon nitrogen $\left(\mathrm{mg}_{\mathrm{C}} / \mathrm{mg}_{\mathrm{N}}\right)$

$\mathrm{P} \quad$ phosphorus concentration $(\mathrm{mg} / \mathrm{l})$

TS total solids concentration $\left(\mathrm{g}_{\mathrm{TS}} / \mathrm{kg}_{\text {support }}\right)$

TVS total volatile solids concentration $\left(\mathrm{g}_{\mathrm{TVS}} / \mathrm{kg}_{\text {support }}\right)$

$\rho_{\text {biofilm }} \quad$ biofilm density $\left(\mathrm{g}_{\mathrm{TVS}} / \mathrm{cm}^{3}{ }_{\text {wet biofilm }}\right)$

$\rho_{\mathrm{f}} \quad$ density of the wet biofilm $\left(\mathrm{g} / \mathrm{cm}^{3}\right)$

$\rho_{\text {bioparticle }}$ bioparticle density $\left(\mathrm{g} / \mathrm{cm}^{3}\right)$

$\rho_{\text {support }}$ density of the bare support $\left(\mathrm{g} / \mathrm{cm}^{3}\right)$

$d_{\mathrm{s}} \quad$ average diameter of the bare support $(\mathrm{mm})$

$L_{\mathrm{f}} \quad$ average thickness of the biofilm (mm)

\footnotetext{
* Corresponding author. Tel.: + 351-253-604411; fax: + 351-253-678986.

E-mail address:mjv@deb.uminho.pt (M.J. Vieira).
} 


\section{Introduction}

Biofilm fluidised bed reactors (FBBR) have received considerable attention in wastewater treatment as reviewed by Heijnen et al. [1]. When compared with suspended biomass systems, these reactors have several advantages including higher biomass concentration, higher sludge age, lower hydraulic residence times, higher volumetric removal rates and relatively small area requirements. The biomass adheres and grows attached to the inert supports, forming a biofilm that consumes the substrates that enter into the reactor. Many materials have been successfully used as support media for biomass immobilisation, including sand, basalt and activated carbon. When the density of the support is high, such as sand and basalt, it is necessary to use small diameter particles to achieve adequate fluidisation conditions. The surface characteristics of the supports (porosity, roughness and electrical charge) are very important in the early stages of biofilm formation (in many situations the supports are seeded outside the reactor or in the reactor but in batch mode, before continuous operation starts). However, during continuous operation, the performance and stability of the reactor depends on the structure of the biofilm formed around the support. Hence, parameters such as biofilm thickness, biofilm density and shape [2,3] and the overall density of the particles covered with biofilm should be controlled to obtain a stable reactor operation.

Biofilm accumulation is a dynamic process that is the net result of growth and the detachment processes and is affected by several external factors, including composition and concentration of the feed, velocity of the liquid phase (shear stress), concentration of particles, particle-particle collisions and particle-wall collisions. During reactor operation, the right balance between the parameters that contribute to biofilm growth and those that affect the detachment from the surface should be attained, in order to obtain steady-state thicknesses. Additionally, the density of the biofilm should be high, in order to achieve a high biomass retention inside the reactor and biofilms resistant to hydrodynamic forces. Moreover, thinner biofilms [4], obtained under higher shear stress are more stable and have a higher active biomass concentration, leading, consequently to higher biofilm activity, that is a key parameter for an optimised bioreactor operation.

In addition to the above mentioned parameters, the nature and the concentration of the substrates may affect biofilm growth and composition. Under a high substrate loading rate, the biofilm accumulation is higher, which can affect the structure formed. The limitation in some nutrients $(\mathrm{C}, \mathrm{N}$ or $\mathrm{P})$ may enhance biopolymer production, instead of cell formation [5] and consequently the concentration of active biomass.
A large number of reports concerned with the structures of biofilms on suspended carriers and their impact on reactor performance are referred to in the literature. Relatively few studies have been carried out in denitrifying fluidised bed reactors with the purpose of studying in detail the biofilm properties formed during reactor operation $[3,6]$. Research regarding pure culture biofilms in fluidised bed reactors is not common in spite of the fact that it can give a good insight on the influence that several parameters have on the structure of the biofilms. This methodology was adopted by some authors [7,8] who studied the properties of biofilms formed on suspended carriers in airlift reactors.

The study reported here concerns the study of the effects of the $\mathrm{C} / \mathrm{N}$ ratio and $\mathrm{P}$ concentration on some parameters of the biofilm-thickness, wet density, total protein and polysaccharide content-formed on basalt particles by Alcaligenes denitrificans in a FBBR used for denitrification, and their influence on reactor performance and stability.

\section{Materials and methods}

\subsection{Microorganism}

The inoculum used to seed the support was a heterotrophic culture of Alcaligenes denitrificans-ATCC 15173 (1985).

\subsection{Support}

Basalt was used as the support medium for biological growth in the reactor. The basalt density was 2.986 $\mathrm{g} / \mathrm{cm}^{3}$ and the average diameter of the particles was $0.839 \mathrm{~mm}$.

\subsection{Bioreactor}

The experimental set-up used consisted of a perspex lab-scale fluidised bed reactor of $1.51 \mathrm{~m}$ height and $0.074 \mathrm{~m}$ internal diameter (Fig. 1). The top of the reactor had an enlarged section to prevent the washout of the particles covered with biofilm. Table 1 summarises the characteristics of the fluidised-bed reactor.

The temperature ranged from 26 to $30{ }^{\circ} \mathrm{C}$ and the $\mathrm{pH}$ was controlled at 7.8 by the supply of $2 \mathrm{M} \mathrm{HCl}$. The reactor was fed continuously with a concentrated solution of potassium citrate in tap water and a concentrated solution of potassium nitrate and potassium phosphate in tap water, by means of a double channel peristaltic pump. Filtered tap water was also added to the reactor, by means of a peristaltic pump, immediately before the reactor input. The total influent rate in the reactor was $10 \mathrm{l} / \mathrm{h}$. The residence time obtained was $1 \mathrm{~h}$. These conditions were chosen to prevent bacterial 


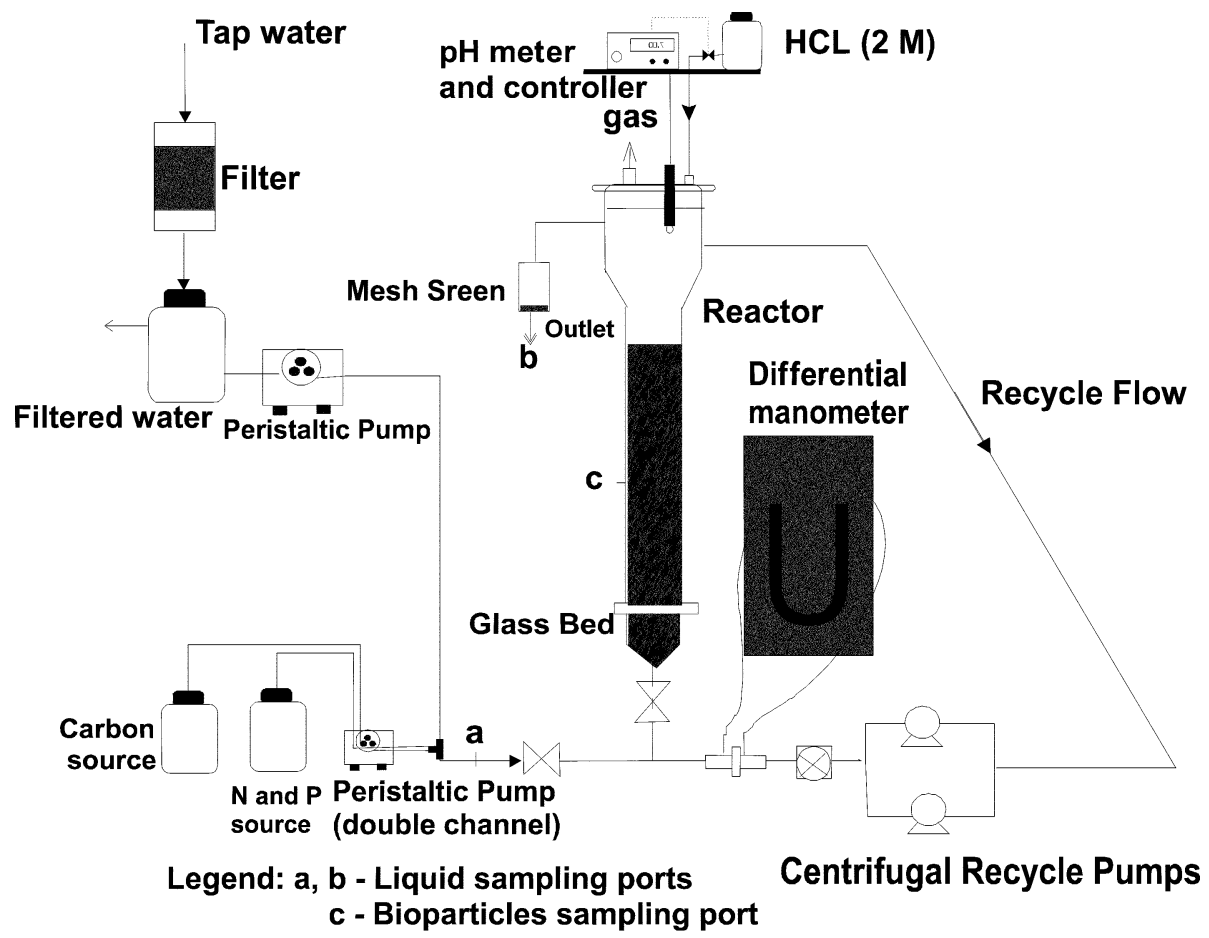

Fig. 1. Schematic representation of the fluidised bed biofilm reactor (FBBR).

growth in suspension and to promote biofilm formation. Part of the effluent was recirculated to the reactor, by means of two centrifugal pumps in parallel, in order to obtain a superficial velocity of $0.055 \mathrm{~m} / \mathrm{s}$ and fluidise the support. Before setting new conditions in the reactor, the biomass formed around the supports were removed by stirring.

\subsection{Wastewater composition (synthetic medium)}

The major substrates used in the denitrification process were nitrate (as electron acceptor) and citrate, the organic carbon source (as electron donor), which were fed separately. Two concentrated solutions were prepared: the first contained the organic carbon (potassium citrate, $\mathrm{C}_{6} \mathrm{H}_{5} \mathrm{~K}_{3} \mathrm{O}_{7} \cdot \mathrm{H}_{2} \mathrm{O}$ ) while the second contained potassium nitrate $\left(\mathrm{KNO}_{3}\right)$, phosphate $\left(\mathrm{KH}_{2} \mathrm{PO}_{4}\right)$ and $100 \mathrm{ml}$ of trace solution. The trace solution contained per 1: $0.2730 \mathrm{~g}$ of $\mathrm{NaMoO}_{4} \cdot 2 \mathrm{H}_{2} \mathrm{O}$, $0.055 \mathrm{~g}$ of $\mathrm{FeSO}_{4}, 0.00909 \mathrm{~g}$ of $\mathrm{MnCl}_{2}, 0.0545 \mathrm{~g}$ of $\mathrm{CaCl}_{2}$ and $2.0 \mathrm{~g}$ of $\mathrm{MgSO}_{4}$.

The inlet flow rates of the concentrated solutions were set in order to obtain the desired $\mathrm{C} / \mathrm{N}$ ratio and phosphorus concentration of each run, as depicted in Table 2.

\subsection{Bioparticles sampling and analysis}

The biofilm characteristics were determined with time for each $\mathrm{C} / \mathrm{N}$ ratio and $\mathrm{P}$ concentration. Particles covered with biofilm (bioparticles) were collected at mid- height of the reactor, every 3 days, throughout each run. This operation was carried out carefully to avoid any shearing of biofilm from the support media. Approximately $2 \mathrm{ml}$ sample of bioparticles was collected and gently washed several times with phosphate buffer

Table 1

Reactor characteristics and operating conditions

\section{Reactor}

Material

Internal diameter

Height

Volume

Perspex transparent column

$0.074 \mathrm{~m}$

$1.51 \mathrm{~m}$

10.91

Operating conditions

Influent flow rate

$10.9 \mathrm{l} / \mathrm{h}$

Recycle ratio

Mean hydraulic retention time

Mean superficial velocity

$95 \pm 3 \%$

$1 \mathrm{~h}$

$0.055 \mathrm{~m} / \mathrm{s}$

Temperature

$\mathrm{pH}$

$28 \pm 2{ }^{\circ} \mathrm{C}$

$7.5 \pm 0.2$

Table 2

$\mathrm{C} / \mathrm{N}$ ratios and $\mathrm{P}$ concentrations used during the different runs

\begin{tabular}{lll}
\hline Run & $\mathrm{C} / \mathrm{N}\left(\mathrm{mg}_{\mathrm{C}} / \mathrm{mg}_{\mathrm{N}}\right)$ & $\mathrm{P}(\mathrm{mg} / \mathrm{l})$ \\
\hline 1 & 1.4 & 0.2 \\
2 & 1.8 & 0.2 \\
3 & 1.8 & 1.1 \\
4 & 3.6 & 1.1 \\
5 & 3.6 & 0.5 \\
\hline
\end{tabular}


to remove any suspended biomass. The bioparticles were immediately stored at $4{ }^{\circ} \mathrm{C}$.

\subsection{Biofilm mass}

The biofilm mass was determined as dry weight: total solids concentration, TS $\left(\mathrm{g}_{\mathrm{TS}} / \mathrm{kg}_{\text {support }}\right)$, and total volatile solids concentration, TVS ( $\mathrm{g}_{\mathrm{TVS}} / \mathrm{kg}_{\text {support }}$ ) according to APHA Standard Methods procedures [9].

\subsection{Average bioparticle diameter and biofilm thickness}

The average biofilm thickness and the average bioparticle diameter were determined by analysing $400-$ 500 bioparticles using a two-dimensional image analysis system. Briefly, this system consisted of a binocular magnifying glass connected to a video linked to a computer.

The data were processed and recorded in the computer using specific software, Global Lab Image (DATA TRANSLATION, Version 3.0). The bioparticles had two different colours: a dark centre that corresponded to the support (basalt), while the biofilm that coated the support transmitted light and was translucent. The biofilm thickness was determined by computing the difference between the area of the support and the area of the support plus biofilm (bioparticle). Each bioparticle was projected and treated as a two-dimensional particle and the software estimated the average area of the projected bioparticle. This average particle area was approximated to a circle area and the average bioparticle diameter was determined. The average bioparticle diameter is defined as a diameter of a circle with the same average superficial area of the observed bioparticle in the image analyser.

\subsection{Biofilm density and bioparticle density}

The biofilm density, $\rho_{\text {biofilm }}\left(\mathrm{g}_{\mathrm{TVS}} / \mathrm{cm}^{3}{ }_{\text {wet biofilm }}\right)$, was determined in duplicate as the amount of dry biomass per volume of wet biofilm, using the equation:

$\rho_{\text {biofilm }}=\frac{m_{\text {dry biofilm }}}{V_{\text {wet biofilm }}}$.

The biofilm wet density and the bioparticle density were determined using the equations of Chang and Rittmann [10]. The density of the wet biofilm $\left(\rho_{\mathrm{f}}\right.$, $\mathrm{g} / \mathrm{cm}^{3}$ ) can be calculated using the biofilm density $\rho_{\text {biofilm }}\left(\mathrm{g}_{\mathrm{TVS}} / \mathrm{cm}^{3}{ }_{\text {wet biofilm }}\right)$, the relationship TVS/ TS and the amount of water in the biofilm, according to

$\rho_{\mathrm{f}}=1.0+\frac{\rho_{\text {biofilm }}}{(\text { TVS } / \text { TS })}$.

The bioparticle density is calculated using the following equation, according to Chang and Rittmann [10]:

$$
\begin{aligned}
\rho_{\text {bioparticle }}= & \rho_{\text {support }}\left(1+\frac{2 L_{\mathrm{f}}}{d_{\mathrm{s}}}\right)^{-3} \\
& +\rho_{\mathrm{f}}\left(1-\left(1+\frac{2 L_{\mathrm{f}}}{d_{\mathrm{s}}}\right)^{-3}\right),
\end{aligned}
$$

where $\rho_{\text {support }}$ and $\rho_{\text {bioparticle }}$ are, respectively, the density of the bare support and of the support covered with biofilm. $d_{\mathrm{s}}$ is the average diameter of the bare support and $L_{\mathrm{f}}$, the average thickness of the biofilm formed around the support.

\subsection{Total biofilm composition}

The total biofilm composition was assessed in terms of total proteins and polysaccharides. After washing the bioparticles carefully with distilled water, they were placed into a known volume of distilled water and the biofilm was detached from the support by ultra-sound treatment for $800 \mathrm{~s}$ (Sonication-Vibra-Cell, Sonics Materials, position 4). The biofilm total protein content was determined using the Lowry modified method (SIGMA-Protein Assay Kit no P5656) with BSA as a protein standard. The exopolysaccharide content was obtained using the phenol-sulphuric method of Dubois et al. [11] with a glucose standard.

\section{Results and discussion}

\subsection{General observations}

In all experimental situations studied, the observation of 40-50 particles showed that all the particles were covered with biofilm. In order to prevent washout of the bioparticles, as frequently reported for fluidised bed reactors $[3,6]$ it was necessary to remove the excess of biomass formed on the carriers. After the removal of the biofilm from the supports, the biofilm accumulated was very low (Fig. 2), by comparing the diameter of the particle in the beginning of the experiment with the diameter of the bare carrier $\left(d_{\mathrm{s}}\right)$. In every case, after some days of operation, it was not possible to obtain a steady-state reactor operation, although the concentration of carbon and nitrate in the effluent reached constant values.

\subsection{Average bioparticle diameter, average biofilm thickness and bioparticle shape}

Figs. 2 and 3 present, respectively, the evolution of the average bioparticle diameter and of the average biofilm thickness accumulated on the basalt particle for the different conditions tested.

Fig. 2 shows that the average diameter of the bioparticles, for each condition tested, increased rapidly with time and that the biofilm accumulation rate depends on the $\mathrm{C} / \mathrm{N}$ ratios and on the concentration of phosphorus. 


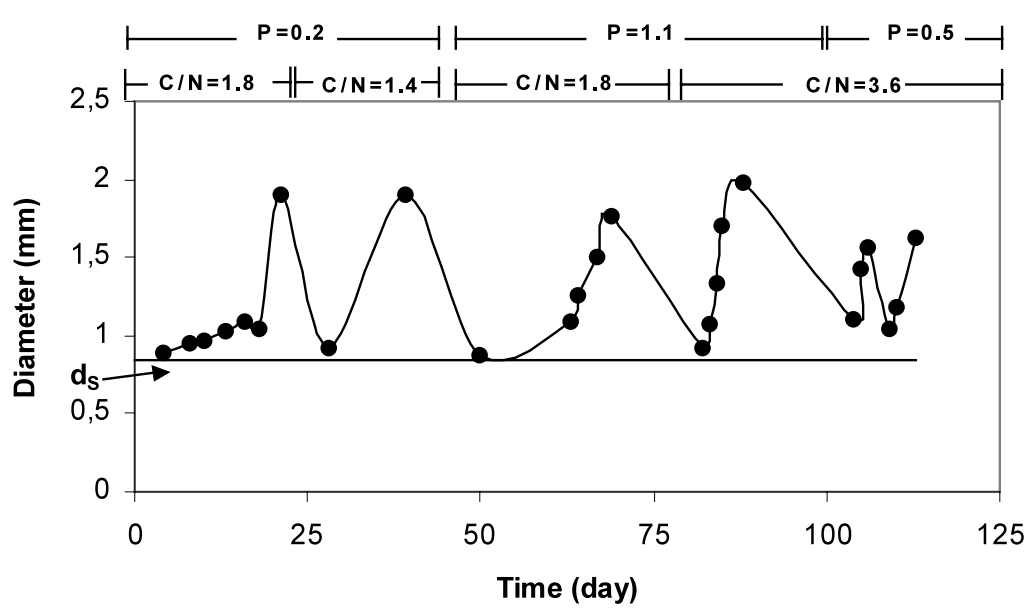

Fig. 2. Average diameter of the bioparticles versus time, for the different $\mathrm{C} / \mathrm{N}$ ratios and $\mathrm{P}$ concentrations (mg/l). The horizontal line corresponds to the average diameter of the bare support $\left(d_{\mathrm{s}}=0.839 \mathrm{~mm}\right)$.

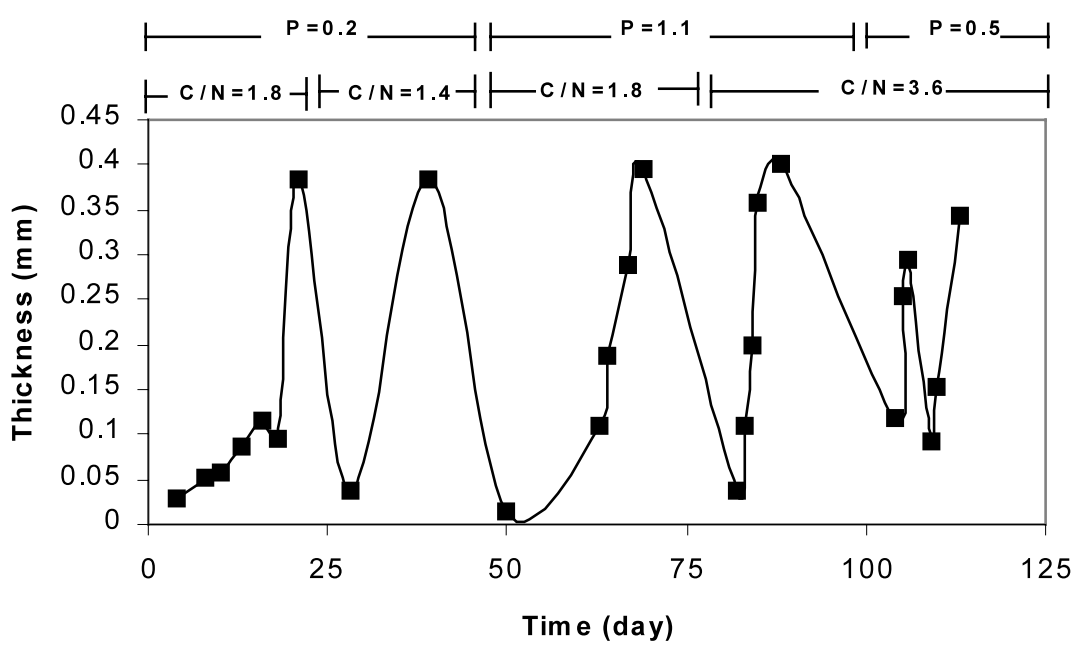

Fig. 3. Average biofilm thickness versus time, for the different $\mathrm{C} / \mathrm{N}$ ratios and $\mathrm{P}$ concentrations $(\mathrm{mg} / \mathrm{l})$.

For all the situations, the average biofilm thickness always increased with time (Fig. 3), and it was not possible to attain a constant value for this parameter, thus leading to conditions of bioparticle washout if the excess of biomass was not removed.

The shape of the particles changed due to biofilm accumulation, becoming more spherical as the biofilm grew (Table 3).

The accumulation of a biofilm on a support is the net result of two competitive phenomena: the production of biomass by the microorganisms in the biofilm and the continuous removal of attached biomass due to the detachment forces (biofilm detachment) caused by the liquid shear, the interactions between the particles and the walls and between the particles themselves. When the growth of the biofilm is higher than the detachment from the surface, the amount of the biofilm around the support increases over time, thereby increasing the diameter of the particle, as depicted in Fig. 2. Thus, it is possible to conclude that the detachment forces at- tained in the reactor were not enough to remove the biomass that was continuously growing around the supports. Although the collisions between particles could account for the detachment of biofilm from the surfaces, according to Gjaltema et al. [12] the detachment rate due to such collisions is mainly attributed to contact between biofilm pellets and bare carriers.

Table 3

Bioparticles shape factor

Shape factor $($ mean \pm S.D. $)$

\begin{tabular}{ll}
\hline Basalt without biofilm (bare support) & $0.8103 \pm 0.0156$ \\
Run & \\
1 & $0.8912 \pm 0.0136$ \\
2 & $0.9013 \pm 0.0312$ \\
3 & $0.8801 \pm 0.0251$ \\
4 & $0.9099 \pm 0.0237$ \\
5 & $0.8766 \pm 0.0321$ \\
\hline
\end{tabular}




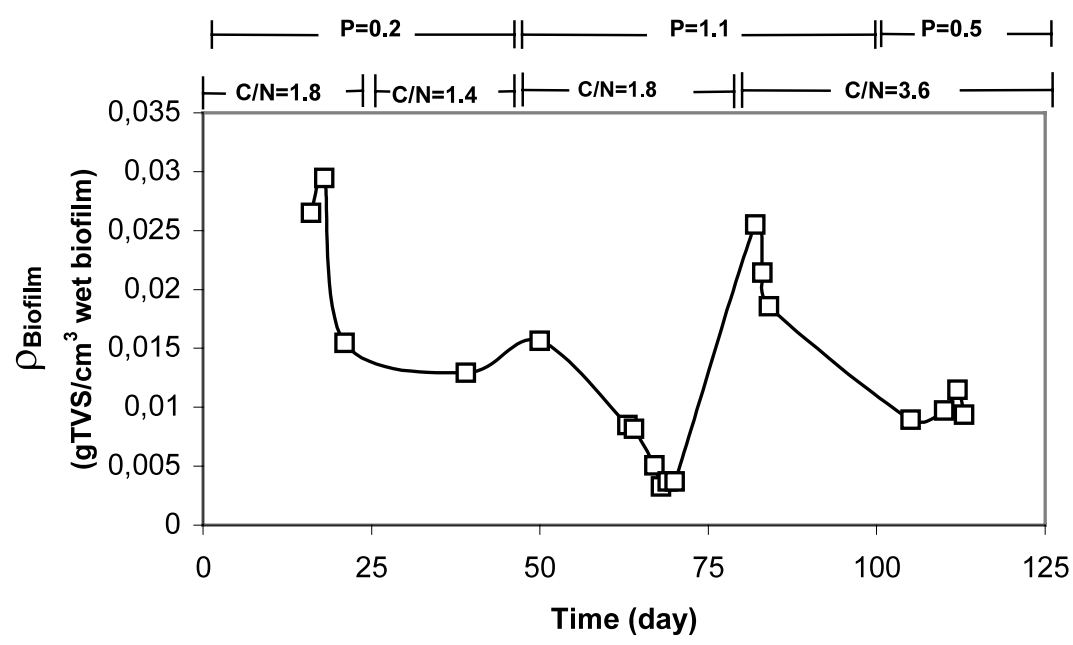

Fig. 4. Densities of the biofilms developed around the basalt particles in the course of the experiments.

Hence, in this case, as all the carriers were covered with biofilm, the level of abrasion is probably low.

Considering the suspended biomass in the effluent as recently formed biomass that was detached from the bioparticles (the operating conditions of the bioreactor were, as mentioned, appropriately chosen to prevent microbial growth in the liquid phase but to promote biofilm formation), the specific mass detachment rate was calculated and very small values were obtained: in the case of run 1 and 2 an average value of $8.28 \mathrm{~g} / \mathrm{day}$ $\mathrm{kg}_{\text {support }}$, while for runs, 3,4 and 5 were obtained average values of $24.98 \mathrm{~g} /$ day $\mathrm{kg}_{\text {support }}$.

\subsection{Biofilm density and bioparticle density}

Fig. 4 presents the densities of the biofilms formed in the course of the experiments. This figure shows that the biofilms formed have low densities. The values obtained are very small compared with the results referred to in the literature for biofilms formed by other microorganisms using reactors with higher shear stresses, or different configurations [2,3].

The balance between the growth of the biofilm and the detachment forces determines the physical structure of the biofilm formed [13]. According to Vieira et al. [14] who studied the effect of the shear stress on biofilms formed by a pure culture of Pseudomonas fluorescens, biofilms formed under high shear stress are thin and dense. Thus, the biofilms formed in these experiments are expected to have low densities. Moreover, Figs. 2 and 3 show that the biofilm accumulation rate is high, which can also contribute for the low density structure, conversely to slow growing microorganisms, as nitrifiers, that form dense biofilms [15].

The density of the biofilm is smaller at the end of each run, for all the conditions tested. These results may be due to the fact that, after the regular washing of the biomass from the supports, the biofilm that remained on the surface was a biofilm composed by cells and low amount of extracellular polymers - a base biofilm [16]. As the biofilm grew, a surface film grew with a different structure with a lower density [15].

Comparing the results obtained for the different $\mathrm{C} / \mathrm{N}$ and $\mathrm{P}$ concentration, different biofilm densities are obtained when those values are varied, which is related, probably, with the different microbial processes occurring inside the biofilms, as it will be discussed later.

The results obtained for the biofilm density will affect, consequently, the density of the bioparticle, as depicted in Fig. 5. For all the situations studied, the bioparticle density decreases $50-55 \%$, approximately 20 days after switching to another nutrient loading condition. The decrease of the overall density of the bioparticles is due to the accumulation of a thick biofilm layer with a lower density than the support, that causes consequently a decrease in the density of the bioparticle. Hence, as the velocity of the fluid is maintained throughout the experiments, the particles have a tendency to move to the upper part of the reactor causing an over expansion of the bed.

These findings have a strong impact on bioreactor stability. The operating conditions in the bioreactor are set-up according to the characteristics of the carriers. If those characteristics change deeply during the operation, as occurred in this work and, if a continuous supervision of the reactor is not carried out, it may affect the reactor operation, namely it may induce washout of the particles from an over-expanded fluidised bed. Consequently, the control of biofilm formation and growth is a key factor for the successful operation of this kind of reactor. 


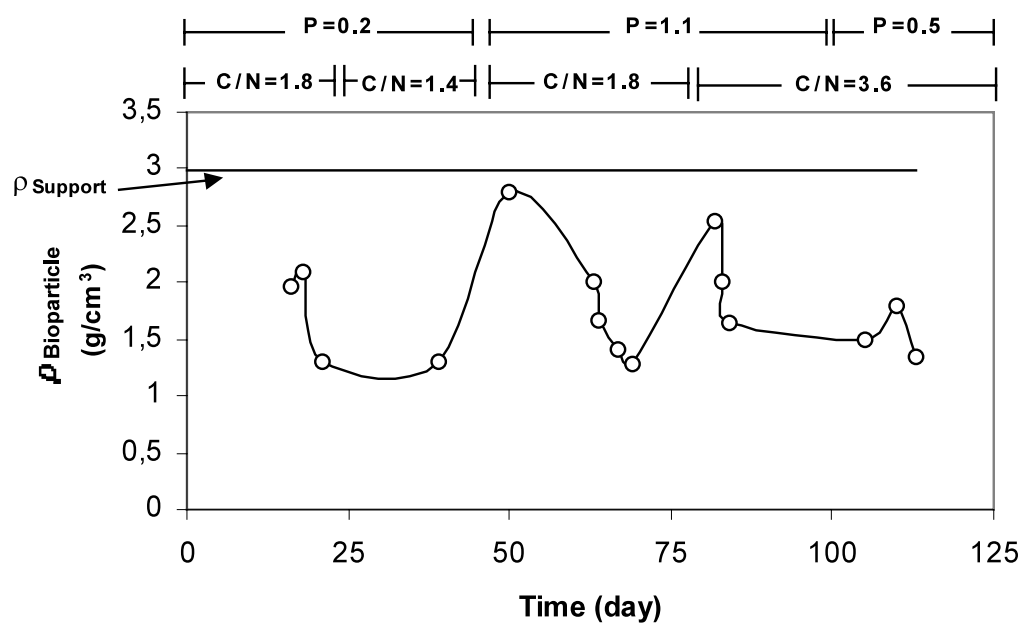

Fig. 5. Overall average density of the bioparticles (concentrations of phosphorus in $\mathrm{mg} / \mathrm{l}$ ). The horizontal line corresponds to the density of the bare support $\left(\rho_{\mathrm{s}}=2.986 \mathrm{~g} / \mathrm{cm}^{3}\right)$.

\subsection{Effect of the $C / N$ ratio and phosphorus concentra- tion on the denitrifying activity and total molecular com- position of the biofilms}

Table 4 presents the results of denitrifying activity (in terms of nitrate removal), percentage of carbon removal, and the average properties of the biofilms, for each condition tested, before the removal of the excess of biomass (before washout conditions).

This Table shows that the $\mathrm{C} / \mathrm{N}$ ratio and phosphorus concentration affect the efficiency of nitrate and carbon removal. For the first situation studied (run 1) the nitrate and carbon removals were very low. An increase in the $\mathrm{C} / \mathrm{N}$ ratio to 1.8 (run 2) slightly increased nitrate removal to $25 \%$. In both cases, as the carbon was not completely removed, it was an indication that another nutrient was a limiting factor. In fact, $100 \%$ carbon removal was achieved by setting the phosphorus concentration at $1.1 \mathrm{mg} / 1$ (run 3). However, nitrate removal was not complete, which was almost obtained by an increase of the $\mathrm{C} / \mathrm{N}$ ratio to 3.6.

From this Table it is also possible to observe that the properties of the biofilm - proteins/polysaccharides ratio, thickness and density are related with the $\mathrm{C} / \mathrm{N}$ ratio and phosphorus concentration.

Fig. 6 presents the relationship between the ratio Proteins/Polysaccharides (Prot/Pol) and the concentration of phosphorus. Increasing the concentration of phosphorus, the ratio Prot/Pol in the biofilms increased and that for the same phosphorus concentration a slightly higher Prot/Pol ratio is attained for a higher $\mathrm{C} / \mathrm{N}$ ratio.

Although the extracellular matrix of the biofilms contains proteins, the protein content of the biofilm may be used as an indirect indicator of biofilm cell concentration [17]. So, a higher Prot/Pol may be related with a higher bacterial cell concentration in relation to the polysaccharide concentration. From the results presented in Table 4, it is possible to observe a concomitant increase of the ratio Prot/Pol and the efficiency of nitrate removal, as the $\mathrm{P}$ concentration increased. Fig. 7 depicts the relation between the percentage of nitrate removal and the ratio of Prot/Pol.

These results may be explained by the fact that a higher phosphorus concentration stimulates cell production in detriment of polymer production, increasing, consequently, the activity of the biofilms. This is in agreement with the results of some authors that reported that a deficiency of some nutrients in the medium can enhance polysaccharide production instead of cell production [5].

Regarding the density of the biofilm, no significant trend was obtained in these experiments, although for the same $\mathrm{C} / \mathrm{N}$ ratios higher densities are obtained for higher phosphorus concentration. The highest density value was obtained when there was not a limitation of nutrients, and a complete removal of nitrate and carbon occurred.

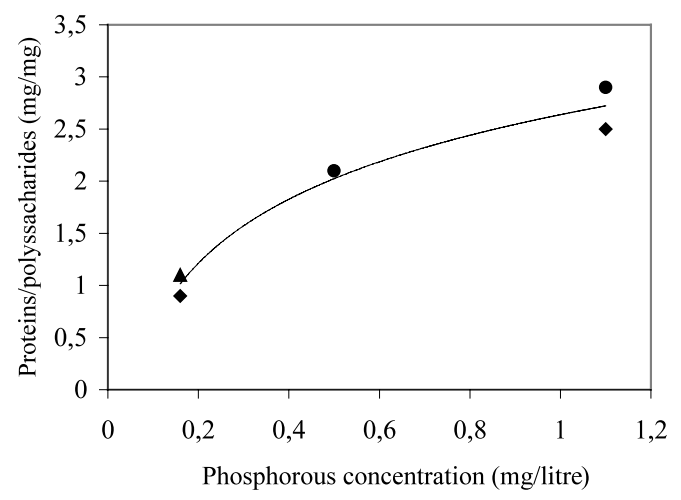

Fig. 6. Influence of the phosphorus concentration on the protein/ polysaccharides ratio at different $\mathrm{C} / \mathrm{N}$ ratios: $(\boldsymbol{\Delta}) 1.4,(\diamond) 1.8$, 3.6. 
Table 4

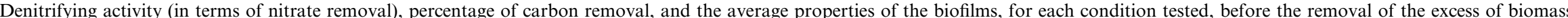
(before washout conditions)

\begin{tabular}{|c|c|c|c|c|c|c|c|}
\hline Run & $\mathrm{C} / \mathrm{N}\left(\mathrm{mg}_{\mathrm{C}} / \mathrm{mg}_{\mathrm{N}}\right)$ & $\begin{array}{l}\text { Phosphorus concentration } \\
(\mathrm{mg} / \mathrm{l})\end{array}$ & $\begin{array}{l}\text { Nitrate removal } \\
(\%)\end{array}$ & $\begin{array}{l}\text { Carbon removal } \\
(\%)\end{array}$ & $\begin{array}{l}\text { Proteins/Polysaccharides } \\
(\mathrm{mg} / \mathrm{mg})\end{array}$ & $\begin{array}{l}\text { Biofilm thickness } \\
(\mu \mathrm{m})\end{array}$ & $\begin{array}{l}\text { Biofilm density } \\
\left(\mathrm{g}_{\mathrm{TVS}} / \mathrm{cm}^{3}{ }_{\text {wet biofilm }}\right)\end{array}$ \\
\hline 1 & 1.4 & 0.2 & 15 & 60 & 1.1 & 384 & 0.0125 \\
\hline 2 & 1.8 & 0.2 & 25 & 50 & 0.9 & 385 & 0.015 \\
\hline 3 & 1.8 & 1.1 & 45 & 100 & 2.5 & 395 & 0.005 \\
\hline 4 & 3.6 & 1.1 & 93 & 93 & 2.9 & 402 & 0.02 \\
\hline 5 & 3.6 & 0.5 & 49 & - & 2.1 & 344 & 0.009 \\
\hline
\end{tabular}




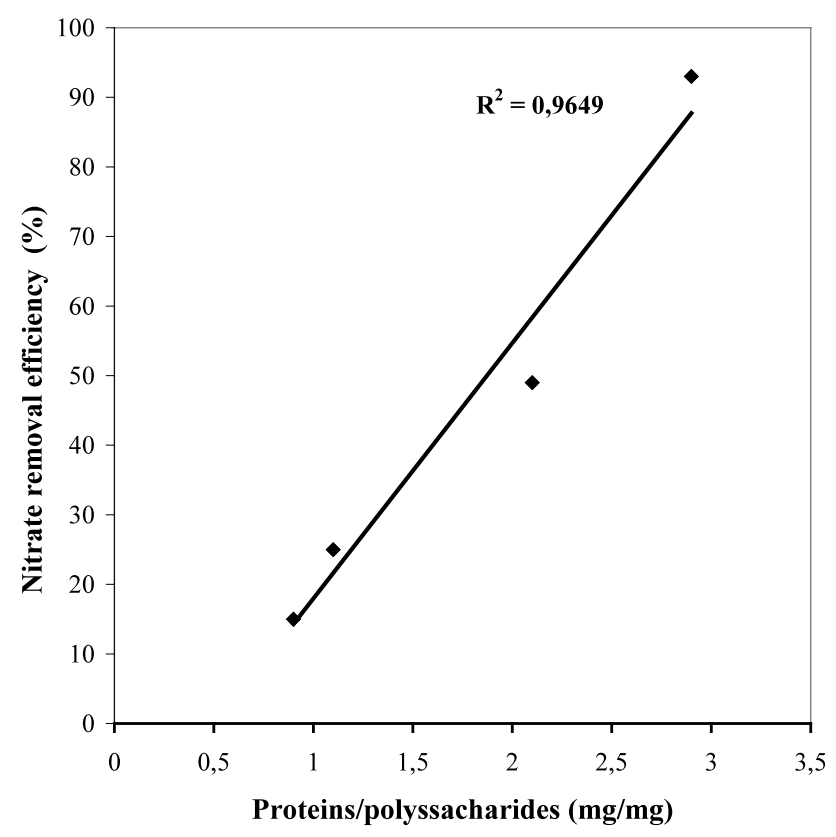

Fig. 7. Correlation between the nitrate removal efficiency and the ratio protein/polysaccharides $(\mathrm{mg} / \mathrm{mg})$.

\section{Conclusions}

The following conclusions can be drawn from the work presented:

Over the experimental range studied, conversely to the removal efficiencies of $\mathrm{C}$ and $\mathrm{N}$ that attained steady-state values, the diameter of the particles (and consequently the thickness of the biofilm) was always increasing, thus reducing the specific biofilm activity.

A denser biofilm was obtained when there was no nutrient limitation that corresponded to complete removal of nitrate and carbon.

The experiments showed that the composition of the biofilm in terms of proteins and polysaccharides changed with the $\mathrm{C} / \mathrm{N}$ ratio and $\mathrm{P}$ concentration in the medium. Higher denitrifying activities, which were attained with increasing $\mathrm{P}$ concentrations, were related with higher protein content. An increase in phosphorus concentration shifted the metabolism from polysaccharide production towards cell production.

In this system, the thickness and the density of the biofilms were related mainly with the shear stress in the reactor (physical phenomena), while the composition of biofilms was dependent on the composition of the medium and related with the higher activity of the microorganisms (biological phenomena).

\section{Acknowledgements}

The authors acknowledge the financial support provided by the programme PRAXIS XXI (Grant PRAXIS XXI/BM/6701/95) and by Instituto de Biotecnologia e Química Fina - IBQF.

\section{References}

[1] Heijnen JJ, Mulder A, Enger W, Hoeks F. Review on the application of anaerobic fluidised bed reactors in wastewater treatment. Chem Eng J 1989;41:B37-50.

[2] Kwok WK, Picioreanu C, Ong SL, van Loosdrecht MCM, Ng WJ, Heijnen JJ. Influence of biomass production and detachment forces on biofilm structures in a biofilm airlift suspension reactor. Biotechnol Bioeng 1998;58:401-7.

[3] Huang J-S, Yan J-L, Wu C-S. Comparative bioparticle and hydrodynamic characteristics of conventional and tapered anaerobic fluidized bed reactors. J Chem Technol Biotechnol 2000;75:269-78.

[4] Vieira MJ, Melo LF. Intrinsic kinetics of biofilms formed under turbulent flow and low substrate concentrations. Bioproc Eng 1999;20:363-8.

[5] Veiga MC, Mendez R, Lema JM. Development and stability of biofilms in bioreactors. In: Melo LF, Bott TR, Fletcher M, Capdeville B, editors. Biofilms - Science and Technology, vol. 223. Netherlands: Kluwer Academic Publishers, 1992:421-34.

[6] Lazarova VZ, Capdeville B, Nikolov L. Biofilm performance of a fluidised bed biofilm reactor for drinking water denitrification. Wat Sci Tech 1992;26:647-54.

[7] Lopes FA, Vieira MJ, Melo LF. Chemical Composition and activity of a biofilm during the start-up of an airl-lift reactor. Wat Sci Tech 2000;4:105-11.

[8] Gjaltema A, van der Marel N, van Loosdrecht MCM, Heijnen JJ. Adhesion and biofilm development on suspended carriers in airlift reactors: hydrodynamics conditions versus surface characteristics. Biotechnol Bioeng 1997;55:880-9.

[9] APHA, Standard Methods for the Examination of Water and Wastewater, 16th ed., Washington, DC, USA, 1985.

[10] Chang HT, Rittmann BE. Predicting bed dynamics in three phase fluidised bed reactors. Wat Sci Tech 1994;29:231-41.

[11] Dubois M, Gilles KA, Hamilton JK, Rebers A, Smith F. Colorimetric method for determination of sugars and related substances. Anal Chem 1956;28:350-6.

[12] Gjaltema A, Vinke N, van Loosdrecht MCM, Heijnen JJ. Abrasion of suspended biofilm pellets in airlift reactors: importance of shape, structure and particle concentration. Biotechnol Bioeng 1997;53:88-99.

[13] van Loosdrecht MCM, Tijhuis L, Wijdieks AMS, Heijnen JJ, Wat. Sci. Tech. 1995; 31: 163-171.

[14] Vieira MJ, Melo LF, Pinheiro MM. Biofilm Formation - hydrodynamic effects on internal diffusion and structure. Biofouling 1993;7:67-80.

[15] van Benthum WAJ, Garrido-Fernández JM, Tijhuis L, van Loosdrecht MCM, Heijnen JJ. Formation and detachment of biofilms and granules in a nitrifying biofilm airlift suspension reactor. Biotechnol Prog 1996;12:764-72.

[16] Peyton BM. Effects of shear stress and substrate loading rate on Pseudomonas aeruginosa biofilm thickness and density. Wat Res 1996;30:29-36.

[17] Lazarova V, Pierzo V, Fontvielle D, Manem J. Integrated approach for biofilm characterisation and biomass activity control. Wat Sci Tech 1994;29:345-54. 